\title{
Azo Dye Acid Blue 29: Biosorption and Phytotoxicity Test
}

\author{
Emi Brinatti Guari • Érica Janaina Rodrigues de Almeida • \\ Maria de Jesus Sutta Martiarena • Nívea Santos Yamagami • \\ Carlos Renato Corso
}

Received: 28 April 2015 / Accepted: 8 September 2015 /Published online: 5 October 2015

(C) Springer International Publishing Switzerland 2015

\begin{abstract}
Many products contain dyes, such as fabrics. However, most of the industry-generated waste is improperly handled, which causes serious environmental problems for the bodies of water that receive textile effluents. This study aimed to analyze the effect of biosorbents and biosorption techniques on decolorizing the textile azo dye Acid Blue 29 in an aqueous solution employing pine sawdust. Pine sawdust is low-cost substrate with minor environmental impact. A toxicity test was performed with Lactuca sativa seeds to determine the $\mathrm{LC}_{50}$ of the dye. Subsequently, a biosorption test was performed to determine the toxicity of the resulting solutions. We observed that biosorption is a very feasible technique for the discoloration of the solutions and promotes reduction in their toxicity.
\end{abstract}

\footnotetext{
E. B. Guari • É. J. R. de Almeida ( $\bowtie) \cdot$

M. de Jesus Sutta Martiarena · N. S. Yamagami · C. R. Corso

Departamento de Bioquímica e Microbiologia, Instituto de Biociências, UNESP-Univ. Estadual Paulista, Campus de Rio Claro 24-A, n¹515, Bela Vista, CEP 13506-900 Rio Claro, SP, Brazil

e-mail: almeidaejr@gmail.com

E. B. Guari

e-mail: emi.brinatti@gmail.com

M. de Jesus Sutta Martiarena

e-mail: mafeansu@hotmail.com

N. S. Yamagami

e-mail: yamagami.nivea@gmail.com

C. R. Corso

e-mail: crcorso@rc.unesp.br
}

Keywords Azo dye - Effluent textile treatment . Adsorption · Pinus sp. $\cdot$ Lactuca sativa

\section{Introduction}

In today's overpopulated and globalized world, conflicts arise regarding the use of space and resources, as well as the proper waste disposal procedures. Over the past two centuries, the prevailing model of industrialization in both work organization and means of production had led to the availability of an enormous variety of chemicals and the consequent generation of waste in quantities that are significantly detrimental to the environment (López et al. 2006). Synthetic dyes are among such substances and are widely used in different industries, such as paints, plastics, and textiles, leading to the production of more than 10,000 different color tones each year (Forgacs et al. 2004).

The textile dyeing process consumes large volumes of water and consequently generates large amounts of effluents. The main characteristic of a dyeing output is a highly saturated color, which stems from excess dye molecules that are not fixed to the textile fibers during the dye baths (Kunz et al. 2002). The improper disposal of these effluents into bodies of water causes considerable harm to the environment, such as decreased phytoplankton biomass. The dye-layered water on the surface prevents the penetration of sunlight and consequently impedes the photosynthetic process (Rahman et al. 2013). Moreover, the contamination of aquatic organisms causes severe dysfunction in the food web of 
various ecosystems and causes many organisms to become unavailable for human consumption (Patil et al. 2009; Corso and Almeida 2009).

The harmful effects of dyes have raised increasing concerns regarding the difficulty of properly treating effluents before their release into bodies of water. Dyes are formed by stable molecules that remain in the environment for long periods of time (Kimura et al. 1999). Toxicity tests can be performed using different organisms, such as plants, to measure the effects of these harmful byproducts of industry (Sobrero and Ronco 2008). Moreover, different measures can be taken to remove dye molecules from industrial effluents before releasing them into the environment. Adsorption consists of the adherence of molecules in a solution to a solid surface, such as sawdust and even microorganisms (Almeida and Corso 2014). The amount of dye adsorbed is dependent on factors such as $\mathrm{pH}$ and the concentration of dye.

The aim of this study was to analyze the effect of biosorbent and biosorption techniques on decolorizing the textile azo dye Acid Blue 29 in an aqueous solution employing pine (Pinus sp.) sawdust. This low-cost, organic substrate was chosen as it is an industry waste product both easily acquirable and rapidly degradable. Thereby, the chosen substrate has a low environmental impact. A toxicity test was also performed with Lactuca sativa seeds to determine the $\mathrm{LC}_{50}$ of the dye. Subsequently, a biosorption test was performed to determine the toxicity of the resulting solution.

\section{Materials and Methods}

\subsection{Azo Dye Acid Blue 29}

Acid Blue 29 (Fig. 1) is a dye manufactured by Aldrich Chemical Company Inc. (CI: 20460), soluble in water, purity $\sim 40 \%$, molecular weight of 616.49 , and the maximum absorbance at $602 \mathrm{~nm}$. The seeds employed

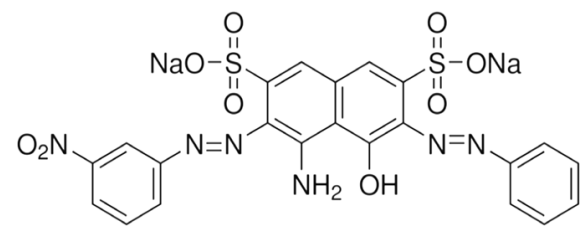

Fig. 1 Chemical structure of Acid Blue 29 dye. Source: SigmaAldrich Chemical Company, Inc in this study were from L. sativa Grand Rapids TBR; 2011/2011 crop; Feltrin brand.

\subsection{Stability Test of Dye Solutions at Two Different $\mathrm{pH}$ Values}

The spectral stability test was performed to determine the stability of the dye at different $\mathrm{pH}$ values (2.5 and 6.5) and whether spectral changes occur in the presence of different hydrogen ion concentrations. The dye solution was used at a concentration of $100 \mu \mathrm{g} / \mathrm{mL}$, and the $\mathrm{pH}$ was adjusted with $\mathrm{HCl}$ and $\mathrm{NaOH}$ at concentrations ranging from 0.01 to $1.00 \mathrm{M}$. These procedures were performed in triplicate. Readings were made in a UV-vis spectrophotometer in the range of $190-750 \mathrm{~nm}$ region in a quartz curvette with an optical path of $5 \mathrm{~mm}$. For calibration of the apparatus, distilled water was used as reference.

\subsection{Preparation of Adsorbent Substrate}

The adsorption tests were performed with raw sawdust (Pinus sp.) ground to achieve a particle size less than 1:41 mm (measured on steel sieve).

\subsection{Adsorption with Pinus sp.}

For the adsorption experiments, $20 \mathrm{~mL}$ of dye solution was used at a concentration of $100 \mu \mathrm{g} / \mathrm{mL}$. The tests were performed at $\mathrm{pH} 2.5$ and 6.5. The solutions were placed in contact with the adsorbent material with different amounts of biomass. The dye solution remained in contact with the adsorbent for a period of $2 \mathrm{~h}$ in a growth chamber with the temperature controlled at $28 \pm$ $2{ }^{\circ} \mathrm{C}$. The supernatant was then centrifuged for $15 \mathrm{~min}$ at $3000 \mathrm{rpm}$. This test was performed in triplicate. After centrifugation, the supernatant of each sample was withdrawn and analyzed in a UV-vis spectrophotometer. Based on the absorbance values (Vitor and Corso 2008), the decoloration capacity was calculated for each of the adsorbents tested (Eq. 1).

decolorization $(\%)=\frac{\text { initial absorbance-final absorbance }}{\text { initial absorbance }} \times 100(1)$

in which initial absorbance $\left(A^{\lambda 602 \mathrm{~nm}}\right)$ is the absorbance of sample with dye but without sawdust and observed absorbance $\left(A^{\lambda 602 \mathrm{~nm}}\right)$ is absorbance after contact between the sawdust and dye. 
Fig. 2 Spectral scan of stability of Acid Blue 29 at $\mathrm{pH} 2.5$ and 6.5; dye concentration is $100 \mu \mathrm{g} / \mathrm{mL}$. The molecular structure of the dye did not change across different $\mathrm{pH}$ values

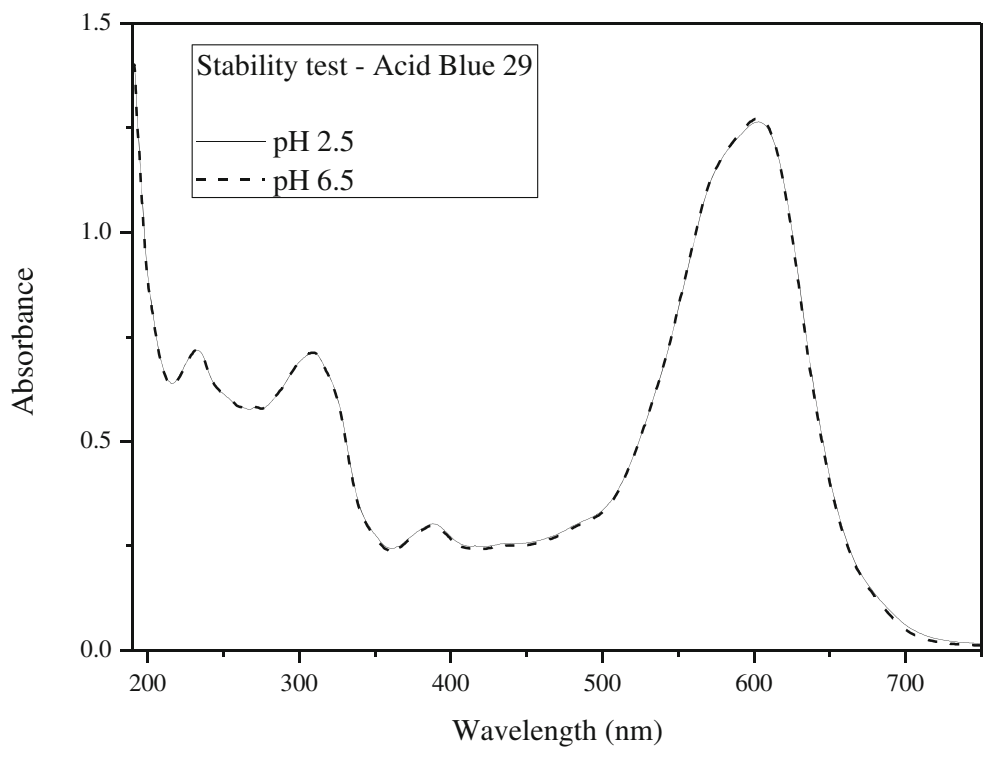

\subsection{Biosorption Isotherms}

After the sawdust tests, the Langmuir and Freundlich equations of biosorption isotherms were applied. Calculations were performed for the remaining concentrations of the dyes and the quantities of dry weight biomass $(\mathrm{mg} / \mathrm{mL})$ used in each test. The isotherms proposed by Allen et al. (2004) and Kurniawan et al. (2012) were employed, as shown in Eqs. 2 and 3 below:
Freundlich isotherm equation

$\log \mathrm{e}=\log K+\frac{1}{n} \cdot \log \mathrm{Cr}$

in which $\mathrm{qe}=$ concentration of dye adsorbed per unit of biomass $(\mathrm{mg} / \mathrm{g}) ; \mathrm{Cr}=$ concentration of dye remaining $(\mathrm{mg} / \mathrm{mL}) ; \log K$ is the $y$ intercept; and $n$ is the slope.
Fig. 3 Comparison of decolorization of Acid Blue 29 solution after adsorption on sawdust at pH 2.5 and 6.5 (initial dye concentration with $100 \mu \mathrm{g} /$ $\mathrm{mL}$ in $28^{\circ} \mathrm{C}$ of temperature, during $2 \mathrm{~h}$ )

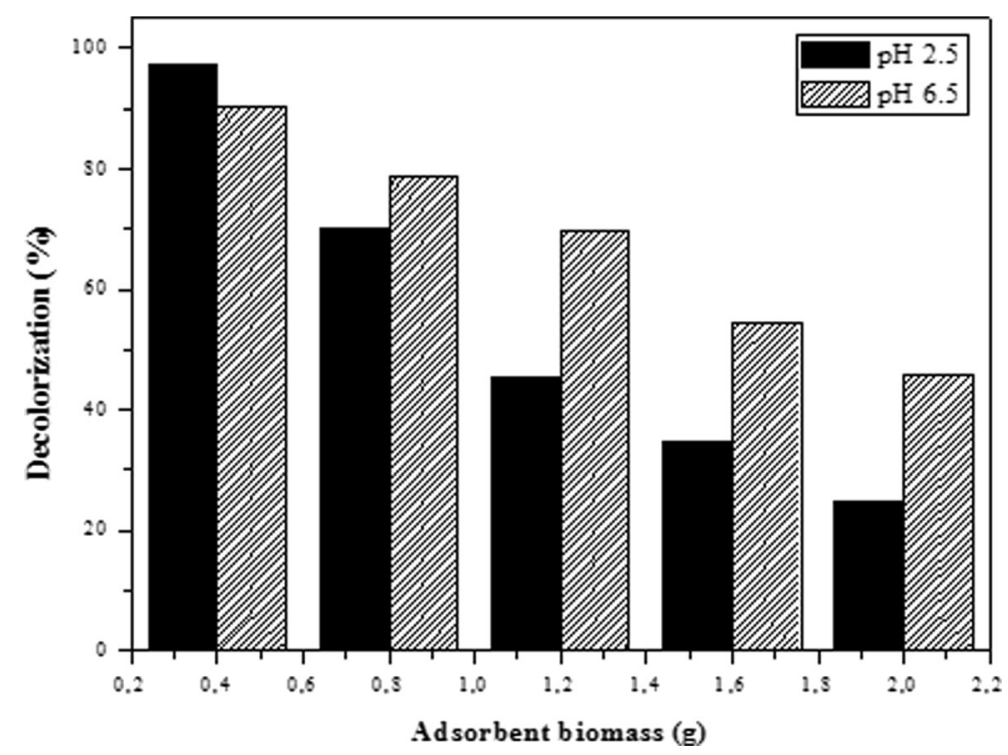


Table 1 Estimation of the amount of pine sawdust required for complete removal of Acid Blue 29 from a solution at an initial concentration of $100 \mu \mathrm{g} / \mathrm{mL}$

\begin{tabular}{llc}
\hline & pH 2.5 & pH 6.5 \\
\hline Sawdust biomass (g) & 2.41 & 3.59 \\
\hline
\end{tabular}

Langmuir isotherm equation

$\frac{\mathrm{Cr}}{\mathrm{qe}}=\frac{1}{\mathrm{~K} 1 . \mathrm{K} 2}+\frac{\mathrm{Cr}}{\mathrm{K} 2}$

in which $\mathrm{K} 1=$ capillarity index expressed in milliliters of dye solution, dye adsorbed at saturation $(1 / \mu \mathrm{g})$ and $\mathrm{K} 2=$ amount of solute that saturates a unit of biomass with a monolayer adsorbent $(\mathrm{mg} / \mathrm{mL})$.

To be able to say that a substance falls into an isotherm, it is necessary for the calculation result to be close to 1 .

\subsection{Phytotoxicity Test with $L$. sativa Seeds}

For the phytotoxicity tests, dye solutions were used at concentrations of 50, $100500,1000,1500,2500$, and $3000 \mu \mathrm{g} / \mathrm{mL}$. The negative control had distilled water only and the positive control had zinc sulfate $\left(\mathrm{ZnSO}_{4}-0.05 \mathrm{~N}\right)$ diluted in distilled water, which inhibits plant growth.
Table 2 Data obtained for Freundlich and Langmuir isotherms at $\mathrm{pH} 2.5$ and 6.5 in $28^{\circ} \mathrm{C}$ of temperature

\begin{tabular}{lll}
\hline $\mathrm{pH}$ & Freundlich isotherm & Langmuir isotherm \\
\hline 2.5 & $R=-0.707$ & $R=0.858$ \\
6.5 & $R=-0.686$ & $R=0.991$ \\
\hline
\end{tabular}

In Petri dishes, 20 L. sativa seeds were placed on filter paper moistened with $3 \mathrm{~mL}$ of each dye solution as well as the positive and negative controls. Each concentration was prepared in triplicate. The dishes were sealed with a plastic film to prevent the evaporation of water and covered with aluminum foil to impede the entrance of light. The dishes were incubated in a B.O.D. chamber at $22 \pm$ $2{ }^{\circ} \mathrm{C}$ for $72 \mathrm{~h}$. After the first $24 \mathrm{~h}$, the seeds germinated were counted. At the end of the experiment, the lengths of hypocotyls and roots of the seedlings were measured with the aid of the ImageJ program (Sobrero and Ronco 2008). The toxicity of the dye was determined by the percentage of growth inhibition of the roots and hypocotyls (Eq. 4). A linear equation was then used to calculate the $\mathrm{LC}_{50}$ of the Acid Blue 29 dye.

$\%$ of inhibition $=\frac{(\text { control growth }- \text { treatment growth })}{\text { control growth }} \times 100$
Fig. 4 Comparison of inhibition of growth of $L$. sativa roots and hypocotyls at different dye concentrations tested after $72 \mathrm{~h}$ in $22{ }^{\circ} \mathrm{C}$

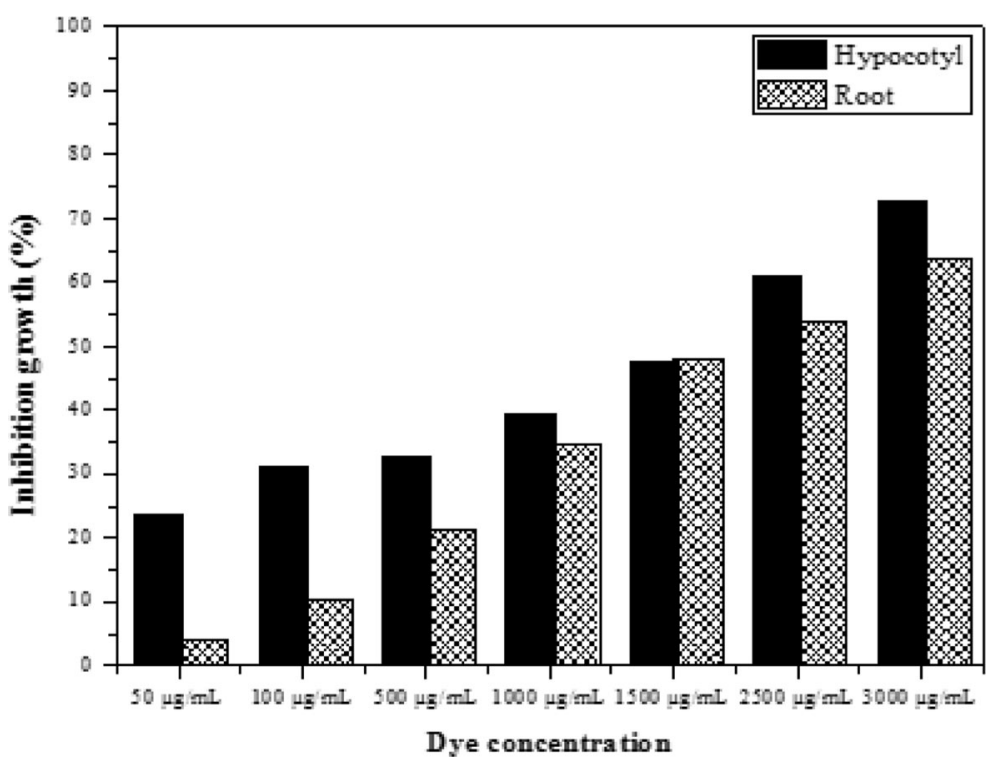




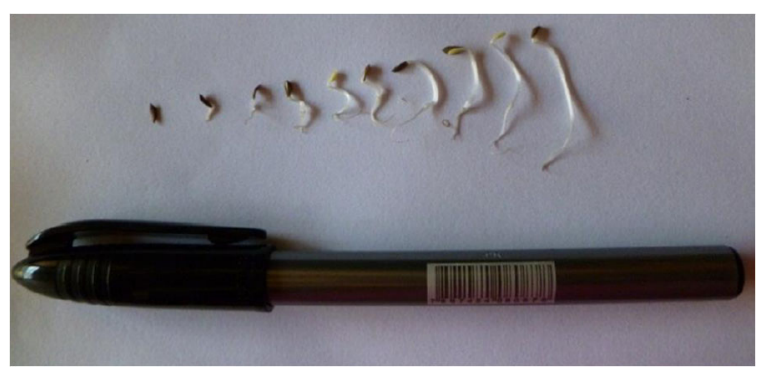

Fig. 5 Root growth of $L$. sativa seeds at different treatments tested (left to right: positive control, dye concentration from highest to lowest concentration, and, lastly, negative control)

\subsection{Phytotoxicity Test After Biosorptive Interaction}

The $\mathrm{LC}_{50}$ concentration $(2106.0 \mu \mathrm{g} / \mathrm{mL})$ was used to conduct a new biosorption performed the same way as described in item 4.6. The supernatant resulting from this test was again subjected to a toxicity test with L. sativa seeds to determine the change in the toxicity of the solution after the biosorptive interaction, which was tested with $0.4,0.8,1.2,1.6$, and $2 \mathrm{~g}$ of biomass.

\section{Results}

\subsection{Stability of Dye Solution at Different pH Values}

Acid Blue 29 dye remained stable when subjected to different $\mathrm{pH}$ values (2.5 and 6.5) (Fig. 2).

\subsection{Biosorption Experiments (Pinus sp.)}

The amount of dye remaining in solutions with sawdust was calculated for the two applied $\mathrm{pH}$ values. Figure 3 shows an increased decoloration of the solutions with the increase in pine sawdust biomass at each $\mathrm{pH}$ value.

The acidic sample ( $\mathrm{pH}$ 2.5) was more efficient regarding the decolorization of the dye. This finding is in agreement with data described by Asgher and Bhatti (2010) for the dyes Reactive Yellow 42 and Reactive Red 45 , wherein the optimum $\mathrm{pH}$ value was 2 , using orange peel (Citrus sinensis) as biosorbent. Studies by Gong et al. (2005) also demonstrate the optimum removal of three anionic dyes (Sunset Yellow, Amaranth, and Fast Green FCF) at $\mathrm{pH}$ 2. This may be explained by the greater availability of cationic sites on the substrate surface in highly acidic media, since a lower $\mathrm{pH}$ enhances the bond between the anionic dye molecules and the cationic surface of the biosorbent, leading to greater color removal.

As for the amount of biomass tested, $2 \mathrm{~g}$ was the most suitable for the success of the test, as a higher concentration of dye in the effluent requires a greater amount of sawdust biomass. Table 1 shows the estimated quantity of sawdust required for the complete removal of dye from a solution at an initial concentration of $100 \mu \mathrm{g} / \mathrm{mL}$, emphasizing, once again, that a more acid $\mathrm{pH}$ of the effluent to be treated will require a smaller amount of sawdust to remove all the dye.
Fig. 6 Spectrum of Acid Blue 29 after biosorption interaction (decolorization of solution, $94.5 \%$ )

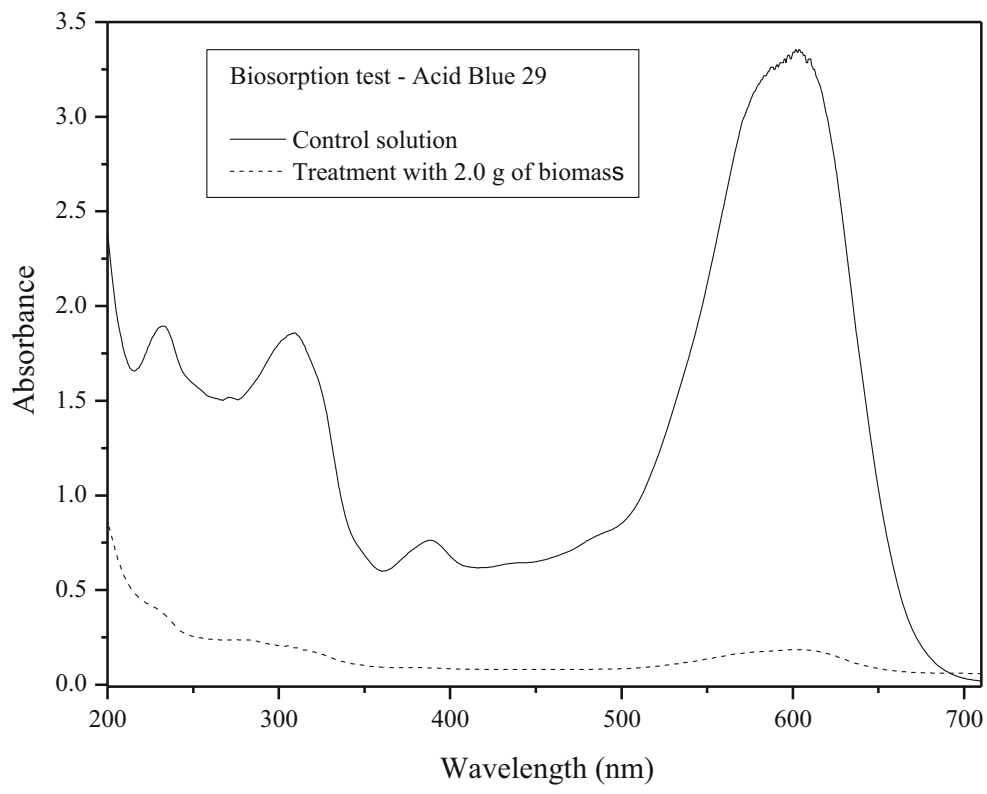




\subsection{Biosorption Isotherms}

The experimental data are shown in Table 2.

The Langmuir isotherm fitted the biosorbent substrate better, since the correlation factor $R$ moved closer to 1 at both $\mathrm{pH}$ values of 2.5 and 6.5 ( $R=0.858$ and 0.991 , respectively). Thus, each adsorbent active site can only accommodate one adsorptive species, that is, the molecules are fixed to the substrate in monolayers. This explains the need for a greater amount of adsorbent for the decolorization of more concentrated dyes.

Mitter et al. (2012) studied adsorption of the dye Acid Violet Alizarin $\mathrm{N}$ with different concentrations of sugarcane bagasse at different $\mathrm{pH}$. The most promising data (achieved with $\mathrm{pH} 2.50$ ) was analyzed with both Freundlich and Langmuir isotherm equations. The model that better fitted this dye was the Freundlich equation with a multilayered model. The dye was characterized with an unstable $\mathrm{pH}$, differently from Acid Blue 29. However Utomo et al. (2015) performed an adsorption study with Methylene Blue using chemically modified sugarcane bagasse, showing that Langmuir adsorption was able to estimate the removal capacity.

\subsection{Phytotoxicity Test with L. sativa}

L. sativa seeds are highly sensitive. At the different concentrations of dye, the roots and hypocotyls demonstrated differentiated reactions to the same amount of dye in terms of growth inhibition (Fig. 4).

The degree of Acid Blue 29 toxicity to L. sativa was the same for the hypocotyls and the roots $\left(\mathrm{LC}_{50}\right.$, $2106 \mu \mathrm{g} / \mathrm{mL}$ ), demonstrating that the roots and hypocotyls are resistant to higher concentrations of Acid Blue 29. Figure 5 shows the difference in root growth among the different treatments.

\subsection{Phytotoxicity After Biosorption Interaction}

The initial solution used in this test was the $\mathrm{LC}_{50}$ determined in the phytotoxicity test described above. However, since the hypocotyl and root had different $\mathrm{LC}_{50}$ values, the higher concentration was used $(2106 \mu \mathrm{g} / \mathrm{mL})$ to cover both situations. After passing through the biosorption process, the concentration of dye in the sample decreased (Fig. 6). Moreover, the toxicity of the Acid Blue 29 aqueous solution also decreased (Table 3).

Growth inhibition after the biosorption test decreased from 50 to $37 \%$ for the roots and 50 to $22 \%$ for the hypocotyl, demonstrating that the toxicity of the dye was successfully reduced (Table 3 ). The initial dye concentration $(2106.0 \mu \mathrm{g} / \mathrm{mL})$ was dropped to $11.70 \mu \mathrm{g} / \mathrm{mL}$ after biosorption interaction held at the $\mathrm{LC}_{50}$. The phytotoxicity test presented increased root growth ranging from $0.90 \mathrm{~cm}$ (before) to $1.20 \mathrm{~cm}$ (after), and the mean hypocotyl growth of $0.84 \mathrm{~cm}$ (before) to $1.06 \mathrm{~cm}$ (after).

The $\mathrm{LC}_{50}$ was lower for the hypocotyl and slightly higher for the roots, demonstrating that the hypocotyl is more sensitive to this dye, which can lead to morphological growth problems in plants and further environmental issues related to the food chain. The toxicity of the dye also extends to other organisms, as the organism used in the toxicity tests were very sensitive to pollutants and demonstrated that this dye can affect other elements in the ecosystem.

Biosorption is a viable solution to the dye waste concern, since it does not break down the dye molecule into more toxic metabolites, as occurs in other color removal techniques for textile effluents. Biosorption is capable of removing the entire molecule from the solution, hence generating less environmental impact. Based on our data, pine sawdust proved to be a good, costeffective, accessible, and organic biosorbent capable of decolorization values up to $94.50 \%$ of an Acid Blue 29 dye solution at an initial concentration of $100 \mu \mathrm{g} / \mathrm{mL}$.

Table 3 Data from phytotoxicity test with L. sativa roots and hypocotyl before and after biosorption

\begin{tabular}{llllll}
\hline $\mathrm{LC}_{50}$ & $\begin{array}{l}\text { Dye concentration } \\
(\mu \mathrm{g} / \mathrm{mL})\end{array}$ & $\begin{array}{l}\text { Mean root growth } \\
(\mathrm{cm})\end{array}$ & $\begin{array}{l}\text { Inhibition } \\
(\%)\end{array}$ & $\begin{array}{l}\text { Mean hypocotyl } \\
\text { growth }(\mathrm{cm})\end{array}$ & $\begin{array}{l}\text { Inhibition } \\
(\%)\end{array}$ \\
\hline Control (-) & 0 & 2.0 & 0 & 1.68 & 0 \\
Before biosorption (dye initial) & 2106 & 0.9 & 50 & 0.84 & 50 \\
After biosorption (dye final) & 11.7 & 1.2 & 37 & 1.06 & 22 \\
\hline
\end{tabular}




\section{Conclusions}

Textile dyes pose extreme harm to ecosystems in general, especially aquatic environments. However, remediation techniques have been tested to reduce this negative impact on the environment. Acid Blue 29 dye was shown to exhibit a high level of toxicity to $L$. sativa seeds, but this toxicity differed based on the structure analyzed. The absorbance spectrum of the dye was stable, thus indicating no significant changes in its molecular structure with variable $\mathrm{pH}$. However, the effect of $\mathrm{pH}$ was more pronounced in acidic medium, requiring smaller amount of adsorbent to remove the same amount of dye.

The isotherms of Langmuir and Freundlich in both $\mathrm{pH}$ values followed the Langmuir model, obtaining values of 0.858 and 0.991 , against Freundlich 0.707 and 0.686.

The phytotoxicity test with $L$. sativa indicated that the hypocotyl was more sensitive than the root, with a significant increase in the inhibition of growth at different dye concentrations.

These results are encouraging, considering the decrease in the percentage of growth inhibition for both roots and hypocotyls in the phytotoxicity tests after biosorption with pine sawdust in contact with the textile solution, which can lead to a less aggressive effluent released into the environment. Further studies are needed to reduce the amount of dye released after the biosorption process, producing a less polluting, less toxic effluent. This study initiates a research field that can be further explored and applied in industries for wastewater treatment.

Acknowledgments Support from the Brazilian fostering agencies Pibic/Pibid, FAPESP/Brazil, CAPES/Brazil, CNPq/Brazil, and Fundunesp/Brazil is acknowledged.

\section{References}

Allen, S. J., Mckay, G., \& Porter, J. F. (2004). Adsorption isotherm models for basic dye adsorption by peat in single and binary component systems. Journal of Colloid and Interface Science, 280, 322-333.

Almeida, E. J. R., \& Corso, C. R. (2014). Comparative study of toxicity of azo dye Procion Red MX-5B following biosorption and biodegradation treatments with the fungi Aspergillus niger and Aspergillus terreus. Chemosphere, 112, 317-322.

Asgher, M., \& Bhatti, H. N. (2010). Mechanistic and kinetic evaluation of biosorption of reactive azo dyes by free, immobilized and chemically treated Citrus sinensis waste biomass. Ecological Engineering, 36, 1660-1665.

Corso, C. R., \& Almeida, A. C. M. (2009). Bioremediation of dyes in textile effluents by Aspergillus oryzae. Microbial Ecology, 57, 384-390.

Forgacs, E., Cserháti, T., \& Oros, G. (2004). Removal of synthetic dyes from wastewaters: a review. Environment International, 30, 953-971.

Gong, R., Ding, Y., Li, M., Yang, C., Liu, H., \& Sun, Y. (2005). Utilization of powdered peanut hull as biosorbent for removal of anionic dyes from aqueous solution. Dyes and Pigments, 64, 187-192.

Kimura, I. Y., Gonçalves, A. C., Jr., Stolberg, J., Laranjeira, M. C. M., \& Fávere, V. T. (1999). Efeito do pH e do tempo de contato na adsorção de corantes reativos por microesferas de quitosana. Polímeros: Ciência e Tecnologia, 9, 51-57.

Kunz, A., Peralta-Zamora, P., Moraes, S. G., \& Durán, N. (2002). Novas tendências no tratamento de efluentes têxteis. Quimica Nova, 25, 78-82.

Kurniawan, A., Sutiono, H., Indraswati, N., \& Ismadji, S. (2012). Removal of basic dyes in binary system by adsorption using rarasaponin-bentonite: revisited of extended Langmuir model. Chemical Engineering Journal, 189-190, 264-274.

López, M. J., Guisado, G., Vargas-Garcia, M. C., Suárez-Estrella, F., \& Moreno, J. (2006). Decolorization of industrial dyes by ligninolytic microorganism isolated from compositing environment. Enzyme and Microbial Technology, 401, 42-45.

Mitter, E. K., Santos, G. C., Almeida, E. J. R., Morão, L. G., Rodrigues, H. D. P., \& Corso, C. R. (2012). Analysis of acid Alizarin Violet $\mathrm{N}$ dye removal using sugarcane bagasse as adsorbent. Water, Air, and Soil Pollution, 223, 765-770.

Patil, P., Desai, N., Govindwar, S., Jadhav, J. P., \& Bapat, V. (2009). Degradation analysis of Reactive Red 198 by hairy roots of Tagetes patula L. (marigold). Planta, 230, 725-735.

Rahman, A., Urabe, T., \& Kishimoto, N. (2013). Color removal of reactive procion dyes by clay adsorbents. Procedia Environmental Sciences, 17, 270-278.

Sobrero, M. S., \& Ronco, A. (2008). Ensayo de toxidad aguda con semillas de lechuga Lactuca sativa L. Ensayos toxicológicos pra la evalucion de susbstancias químicas em agua y suelo (Vol. 1, pp. 55-68).

Utomo, H. D., Phoon, R. Y. N., Shen, Z., \& Ng, L. H. (2015). Removal of Methylene Blue using chemically modified sugarcane bagasse. Natural Resources, 6, 209-220.

Vitor, V., \& Corso, C. R. (2008). Decolorization of textile dye by Candida albicans isolated from industrial effluents. Journal of Industrial Microbiology and Biotechnology, 35, 13531357. 